\title{
DYNAMIC HIGH-TEMPERATURE-PHOSPHOR THERMOMETRY
}

\author{
K. W. Tobin \\ G. J. Capps \\ J. D. Muhs \\ D. B. Smith \\ M. R. Cates
}

Applied Technology Division

Date Published-August 1990

Prepared by the

Oak Ridge National Laboratory

Oak Ridge, Tennessee 37831-7294

operated by

MARTIN MARIETTA ENERGY SYSTEMS, INC.

for the

U.S. DEPARTMENT OF ENERGY

under contract DE-AC05-84OR21400 


\section{CONTENTS}

LIST OF FIGURES $\ldots \ldots \ldots \ldots \ldots \ldots \ldots \ldots \ldots \ldots \ldots \ldots \ldots \ldots \ldots \ldots \ldots \ldots$

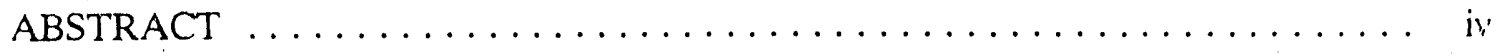

INTRODUCTION $\ldots \ldots \ldots \ldots \ldots \ldots \ldots \ldots \ldots \ldots \ldots \ldots \ldots \ldots \ldots \ldots$

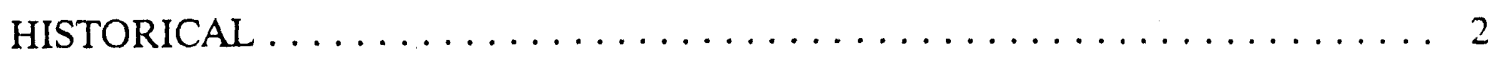

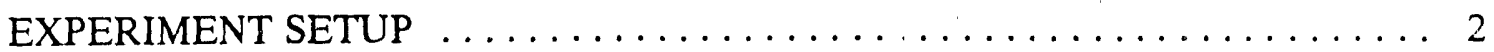

CALCULATION OF TEMPERATURE $\ldots \ldots \ldots \ldots \ldots \ldots \ldots \ldots \ldots \ldots$

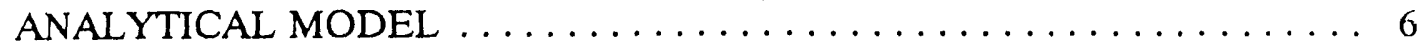

PHOSPHOR CALIBRATION $\ldots \ldots \ldots \ldots \ldots \ldots \ldots \ldots \ldots \ldots \ldots \ldots \ldots \ldots \ldots \ldots$

EXPERIMENT AND RESULTS $\ldots \ldots \ldots \ldots \ldots \ldots \ldots \ldots \ldots \ldots \ldots$

CONCLUSIONS $\ldots \ldots \ldots \ldots \ldots \ldots \ldots \ldots \ldots \ldots \ldots \ldots \ldots \ldots \ldots \ldots \ldots \ldots \ldots \ldots \ldots \ldots$

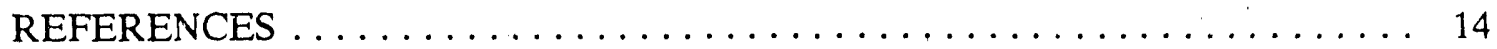




\section{LIST OF FIGURES}

Page

1 Simple $\mathrm{RC}$ circuit used to generate transient heating in a filament wire. . . . . 3

2. Schematic diagram of the transient-heating system showing timing and

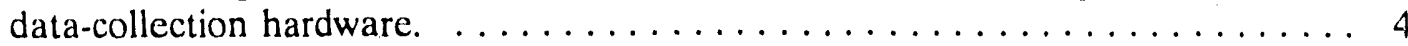

3 Detail of fiber-optic collection probe used to collect the fluorescent

emission from the heated filament. ...................... 5

4 Example of fluorescent signals and relay-timing signal for the transient-

heating system. Note the time delay of $24 \mathrm{~ms}$ between the actuation of the mechanical relay and quenching. ..................... 5

5 Analytical estimate of the expected transient-heating-system response. $\ldots \ldots \ldots 7$

6 Emission spectrum of the $\mathrm{YVO}_{4}$ :Eu phosphor showing the spectral peaks used for the ratio measurement. .................. 8

7 Calibration curve for the ratio formed using a 540- and 620-nm narrowband filter on the $\mathrm{YVO}_{4}$ :Eu emission. ................. 8

8 Representative trace of the two selected spectral components over a single period of the UV-light source during a $10-\mathrm{V}$ heating transient. . . . . . . . 10

9 Ratio of the two spectral components during a $10-\mathrm{V}$ heating transient. Note the useful measurement region of $\sim 7 \mathrm{~ms} . \ldots \ldots \ldots \ldots \ldots \ldots \ldots$

10 Transient temperature results obtained from the $\mathrm{RC}$-heating system ranging from room temperature to near $500^{\circ} \mathrm{C} \ldots \ldots \ldots \ldots \ldots \ldots \ldots \ldots \ldots$

11 Representative heating rates for $0-, 10-$, and $14-\mathrm{V}$ heating transients. $\ldots \ldots \ldots 12$ 


\begin{abstract}
Dynamic surface phosphor thermometry is being investigated as part of a continuing effort by the Applied Technology Division (ATD) at Oak Ridge National Laboratory (ORNL) to develop and apply thermographic phosphor technology to an ever expanding thermometry field. The purpose of this program is to develop dynamic surface phosphor thermometry to a stage where funding proposals can be strengthened by establishing a strong information base and demonstrating a sound capability. As a new technology development in an area well established by ATD/ORNL, dynamic thermometry is extremely important for high-temperature materials, superconducting materials, advanced turbomachinery, space vehicles, industrial process equipment, and other development areas.

This laboratory project illustrated the technique of continuously monitoring dynamic temperature excursions using phosphor thermography. Temperature-increase rates on the order of 100 or more degrees centigrade per millisecond were measured, which illustrated a temporal response of $>0.001 \mathrm{~s}$. This exceeded by a factor of ten the goal for the project and gave strong encouragement for further development of the technology. Important to the project, too, was the establishment of a clear analytical base for fluorescent-ratio data. Using the results of this study, specific solutions to dynamic-temperature-measurement problems in many application areas can be developed. In addition, the dynamicthermographic technology can be coupled with strain measurement, two-dimensional analysis, and thermometry at very high temperatures to add interrelating remotemeasurement tools for systems that currently cannot be effectively studied.
\end{abstract}




\section{INTRODIJCTION}

Dynamic surface-phosphor-thermometry is being investigated as part of a continuing effort by personnel in the Applied Technology Division (ATD) to develop and apply thermographic-phosphor technology to an ever-expanding thermometry field. The purpose of this program is to develop dynamic surface-phosphor thermometry. As a new technology development in an area well established by ATD researchers at Oak Ridge National Laboratory (ORNL), dynamic thermometry is extremely important for high-temperature materials, superconducting materials, advanced turbomachinery, space vehicles, industrial process equipment, and other development areas.

To date, application of phosphor methods to transient systems has been minimal. A majority of testing in many different and unique environments, from turbomachinery to cryogenic systems, has been performed with time/temperature sampling for about several seconds. The proposed goal of the present work is to increase the time resolution of a phosphor-based thermometry system by at least two orders of magnitude $(\sim 0.01 \mathrm{~s})$. The method chosen to achieve this goal is based on using the amplitude (or intensity) ratio method of phosphor thermography using a pseudocontinuous ultraviolet (UV) illumination source. A transient heating device was developed based on resistive heating of a thin filament in a simple $\mathrm{RC}$ circuit with a response time of $\sim 0.001 \mathrm{~s}$.

The fluorescence spectrum of a rare-earth- $\mathrm{dc}_{\mathrm{i}}$ ed phosphor is comprised of emission lines that are characteristic of the particular phosphor. The lines are produced by the radiative de-excitation of the dopant atoms in the host lattice, ${ }^{1}$ and it is well known that the line intensities and emission lifetimes are temperature-dependent properties. A phosphor that is used for its temperature-dependent properties is referred to as a thermographic phosphor. If a thermographic phosphor is excited by a pulsed or continuous source of radiation (by a laser or arc lamp, for example), the ratio of the intensities of two emission lines is a unique function of temperature. By knowing the temperature dependence of this ratio, it is possible to assess the temperature of the phosphor within the range for which the dependence is known or calibrated. Furthermore, when a surface is coated with a thin film of thermographic phosphor, the temperature of the surface can be determined by measuring the intensity ratio. This technique can overcome many of the limitations imposed by a more common thermal-mapping heat-transfer techniques. The technique does not require a uniform illumination of the surface under examination, and it requires only an illumination intensity sufficient to produce the emission lines. The relative intensities of the emission lines are insensitive to both the angle of illumination and the angle of detection, provided both lines are detected at the same location. Also, the ratio technique is self-normalizing, which means that no initial temporal data must be maintained for correction.

The phosphor-ratio method has the advantage over other phosphor techniques in that determination of temperature is independent of geometric distortions and illumination changes as the object undergoes stress. An advantage also exists over nonphosphor-based measurements, such as optical pyrometry, in that the narrow-band filtering of fluorescent emissions inherently discriminates against background noise arising from blackbody radiation. ${ }^{2}$ Also, the phosphor technique is not transmissivity and emissivity dependent. 
HISTORICAL

Thermographic-phosphor development and testing to date by ORNL researchers include high-temperature-furnace and atmospheric-combustor-chamber analysis to determine the degradation effects associated with different bonding methods. ${ }^{3}$ There have been stationary high-temperature spectrophotometer studies to determine temperature-sensitive spectral properties and dependencies, ${ }^{3,4}$ and rotating ambient-temperature spin-rig tests to verify optical and electronic systems. The first temperature measurement on a component immersed in flame was conducted at the Arnold Engineering Development Center (AEDC) High Altitude Test Cell in Tullahoma, Tennessee. ${ }^{5}$ Phosphor was coated on a variable-area ejector located at the exhaust section of a turbine engine. Temperature data were collected while looking through a high-velocity afterburner flame. A rotating flame test was conducted in the atmospheric-combustor rig at Pratt \& Whitney in East Hartford, Connecticut. ${ }^{6}$ This test resulted in a series of temperature measurements made on a phosphor-coated rotating test vane immersed in a jet-flame spray. The first in-engine phosphor tests were recently completed. The first of these was a fixed-blade test that measured temperature on the first-stage stator of a Pratt \& Whitney PW2037 turbine engine. ${ }^{7}$ The second test was performed on the first-stage turbine (rotating geometry) of a Pratt \& Whitney JT15D turbofan engine to evaluate the application of phosphor thermography to high-speed rotating in-engine surfaces. ${ }^{7}$ Recently, testing of thermographic phosphors for cryogenic measurements has also been established by ATD/ORNL. ${ }^{8}$

A majority of the thermographic phosphor experimentation performed to date has been based on a determination of decay lifetimes. Recently, the amplitude-ratio method was further investigated through the development of a method for two-dimensional temperature analysis of wind tunnel models at AEDC. ${ }^{9}$ The ratio method was presented for mitigating imaging artifacts inherent in the phosphor technique currently employed by AEDC. A measurement system was produced using 80286 computer technology with readily available image-processing hardware. This represented the first successful attempt by ATD/ORNL to perform two-dimensional calibrated surface temperature measurements in a static environment. The following work un transient measurements represents the first attempt to characterize and quantify the time-response characteristics of the phosphor-ratio technique in a one-dimensional environment with a self-evident extension to a twodimensional environment.

\section{EXPERIMENT SETIIP}

An experiment was designed to demonstrate the transient-temperature-measurement capability of a thermographic phosphor. The transient heating element of the system was a thin filament used as a resistor in a simple resistance-capacitance $(R C)$ circuit as depicted in Fig. 1. This filament was coated with a thin film of phosphor and monitored with a dual fiber-optic probe. When actuated, the filament underwent fast exponential heating that was well defined and controllable by varying the supplied voltage. The capacitance was chosen such that the heating rate controlling $\mathrm{RC}$ constant was $-0.001 / \mathrm{s}$-an order of magnitude greater than the temporal resolution goal of $0.01 \mathrm{~s}$ 


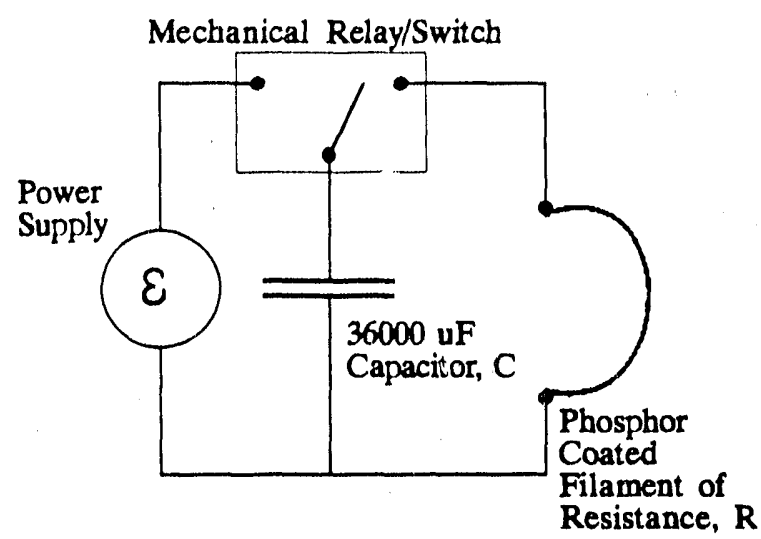

Fig. 1. Simple RCcircuit used to generate transient heating in a filament wire.

Figure 2 is a schematic representation of the overall transient heating system showing the timing and data-collection setup. The timing reference for actuating the mechanical relay of the RC circuit was generated from the output of a fluorescent UV-light source whose amplitude followed the trace of the rectified $60-\mathrm{Hz}$ line voltage (i.e., the UV amplitude oscillated on/off at $120 \mathrm{~Hz}$ ). The on-cycle of the illumination source was $\sim 8.3 \mathrm{~ms}$ and therefore useful as a pseudocontinuous illumination for transients of $<8.3$-ms duration. The UV lamp was monitored with a photodiode whose output was amplified and then pulse shaped (pulser 1 in Fig. 2). The output of the shaper was a $120-\mathrm{Hz}$ syncsource that was then divided by two seriaily connected countdown devices resulting in a pulse-source period of $8.3 \mathrm{~ms}$ to $2.3 \mathrm{~h}$. A longer period $(-5-20 \mathrm{~s})$ was required to allow for sufficient charging of the capacitor prior to heating the filament.

The syncpulse that resulted was then fed into a delay unit. Two channels of the delay device were incorporated. The first channel was shaped (pulser 2 in Fig. 2) and used to drive a high-current operational amplifier whose output actuated a mechanical relay. The second channel of the delay unit was used to trigger the data acquisition system that consisted of a Tektronix-7854 programmable oscilloscope connected to a GPIB interface on an $80286 \mathrm{PC} / \mathrm{AT}$ Tcomputer.

A mechanical relay was used in the measurement system due to the large instantaneous currents generated in the $\mathrm{RC}$ circuit (analytical model estimates an instantaneous current flow of $400 \mathrm{~A}$ ). Several solid-state relays were tested with little success due to their inherent current limitations. The difficulty associated with the mechanical relay was related to the physical bouncing of the contacts after the device was actuated. It was determined that the bounce period of the contacts was on the order of tens of ritliseconds and that a majority of the capacitor energy was transferred through the circuit on the initial contact, therefore causing the phosphor to sufficiently quench. 


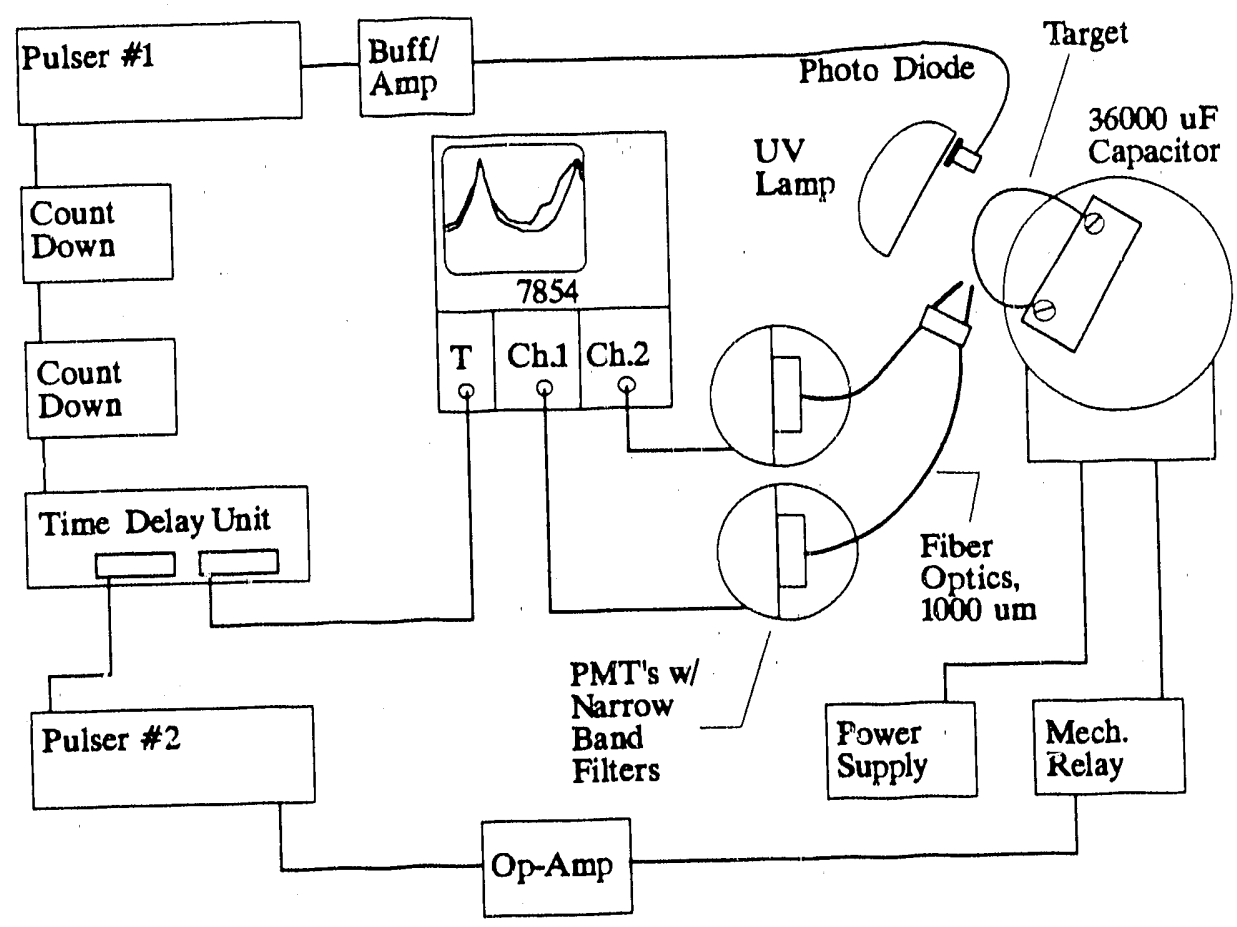

Fig. 2. Schematic diagram of the transient-heating system showing timing and data-collection hardware.

Once the relay was actuated, the capacitor was discharged through the phosphor-coated filament, causing heating. The phosphor coating on the wire responded by quenching or changing emission amplitude according to the surface temperature. The phosphor fluorescence was collected by two fiber optics (1000- $\mu \mathrm{m}$-diam core) as detailed in Fig. 3. The field of view of the two fibers was designed to overlap so that the emission information would be approximately identical. The collected spectrum from the phosphor was sent to two separate photomultiplier tubes (PMT's), each having a different narrow-band filter for spectral selection of the temperature-sensitive information. This process allowed for concurrent collection to two spectral components of the fluorescent emission. The voltage signals produced by the PMTs were then sampled by the 7854 oscilloscope and later transferred to the PC for further analysis.

An example of the collected fluorescent information from the dual-fiber system and the timing signal associated with the mechanical relay is shown in Fig. 4. Note the $\varepsilon .3-\mathrm{ms}$ period of the fluorescence as the phosphor emission follows the illumination amplitude. Also, note the delay between the time of the trigger pulse for the relay and the actual onset of phosphor quenching ( $24-\mathrm{ms}$ delay). This delay is attributed to the amount of time necessary for the relay, once actuated, to make contact and discharge the capacitor. Also present in this figure is an indication of tie relay bounce two cycles later. The information within the box, at $24 \mathrm{~ms}$, was analyzed to determine temperature response. 


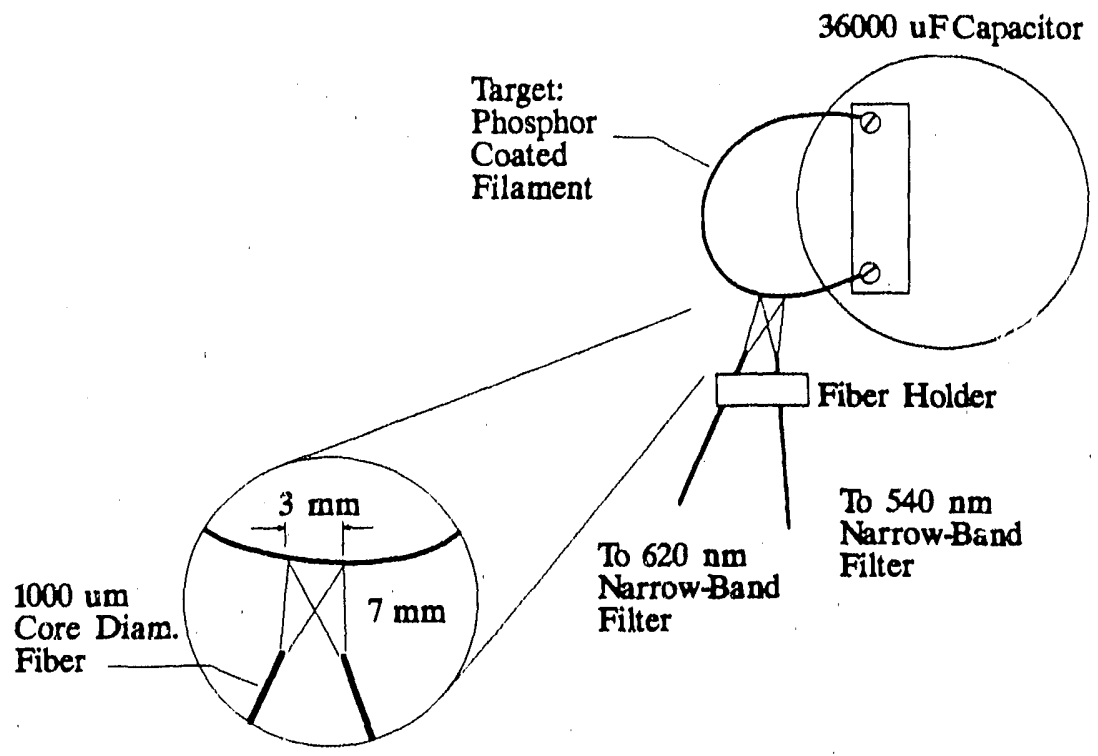

Fig. 3. Detail of fiber-optic collection probe used to collect the fluorescent emission from the heated filament.

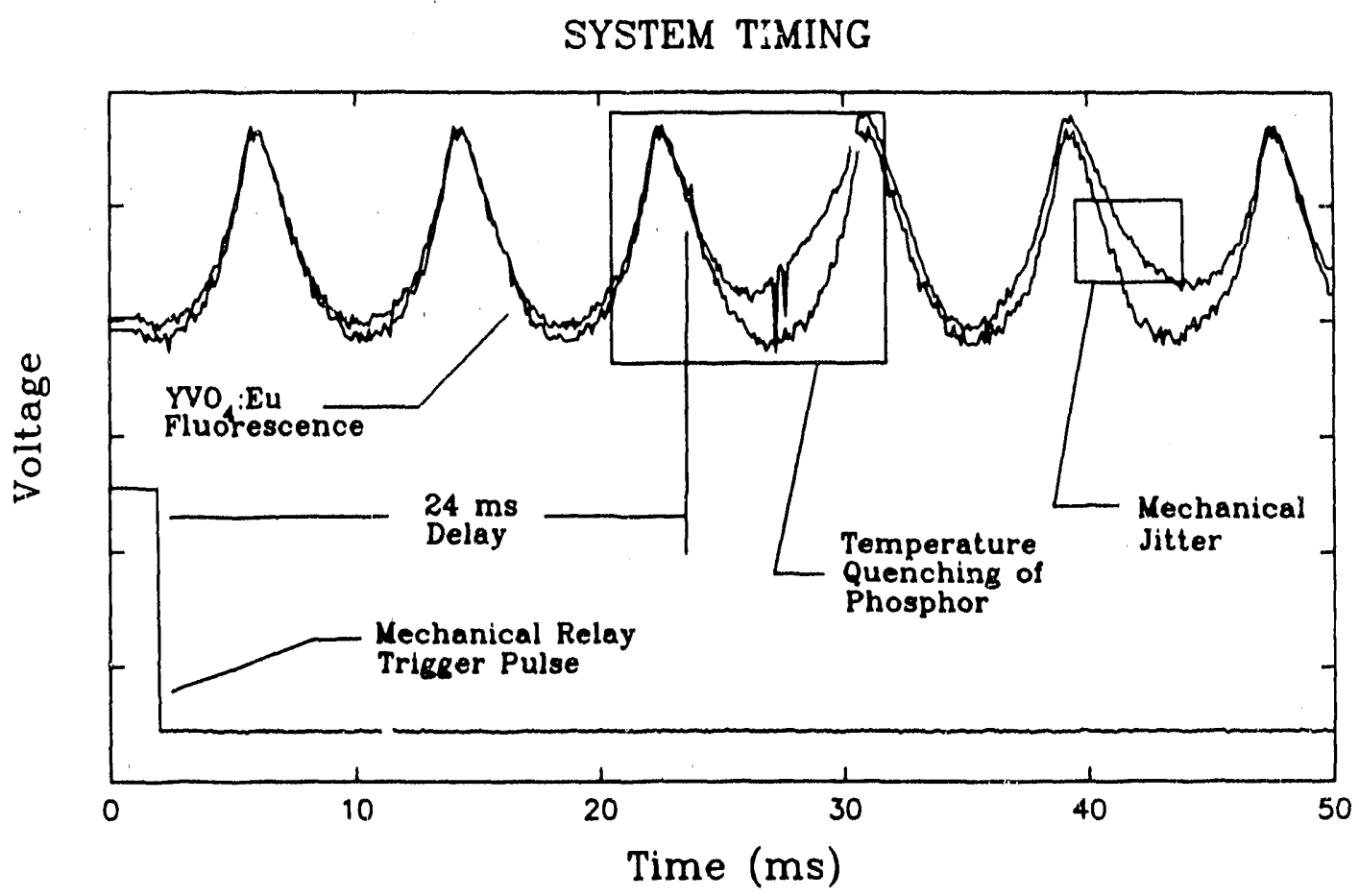

Fig. 4. Example of fluorescent signals and relay-timing signal for the transient-heating system. Note the time delay of $24 \mathrm{~ms}$ between the actuation of the mechanical relay and quenching. 


\section{CALCULATION OF TEMPERATURE}

\section{ANALYTICAL MODEL}

The RC-heating system was chosen as an effective means of generating the required temperature transients because it is well-defined and simple to model. Because there is a set temporal goal of $0.01-\mathrm{s}$ thermal-response time to achieve for this work, a fully controllable system was imperative in the design. The $\mathrm{RC}$-response time of $0.001 \mathrm{~s}$ was selected for the exponential heat rate because this response was much faster than the required measurement, yet much slower than the theoretical limitation on thermographicphosphor time response, which is about the same as the phosphor-decay lifetime (i.e, microseconds). The capacitance and supplied voltage levels for the system were chosen based on the following model. by $^{10}$

Recall that the current flow in a discharging RC circrit such as that in Fig. 1 is given

$$
I(t)=\frac{\varepsilon}{R} e^{-\ell / R C}
$$

where

$$
\begin{aligned}
& \mathrm{I}(\mathrm{t})=\text { current } \\
& \varepsilon=\text { initial voltage } \\
& \mathrm{C}=\text { capacitance } \\
& \mathrm{R}=\text { filament resistance. }
\end{aligned}
$$

The rate of energy dissipation in the resistor filament is $\mathrm{dW}(\mathrm{t}) / \mathrm{dt}=\mathrm{I}^{2}(\mathrm{t}) \mathrm{R}$. Therefore, the energy dissipated at a given time, $t$, is

$$
W(t)=\frac{\varepsilon^{2} C}{2}\left[1-e^{-2 / R C}\right]
$$

If the amount of radiative and conductive heat transfer from the heated element is considered negligible over the period of the transient, then the temperature of the filament can be estimated from the relation ${ }^{11}$

$$
W(t)=\rho V c_{p} \Delta T(t)
$$

where $\rho, V$, and $c_{p}$, are the filament density, volume, and specific heat, respectively. From Eqs. (2) and (3), the expected temperature rise will be given by

$$
\Delta T(t)=\frac{\varepsilon^{2} C}{2 \rho V c_{p}}\left[1-e^{-2 \downarrow R C}\right]
$$


Figure 5 shows the expected response of the designed system to various initial voltage levels for the chosen capacitance and estimated filament resistance. Note that similar voltages are used in the actual system for obtaining transient-response data as will be shown in the following sections.

TRANSIENT HEATING RESPONSE

Analytical Model

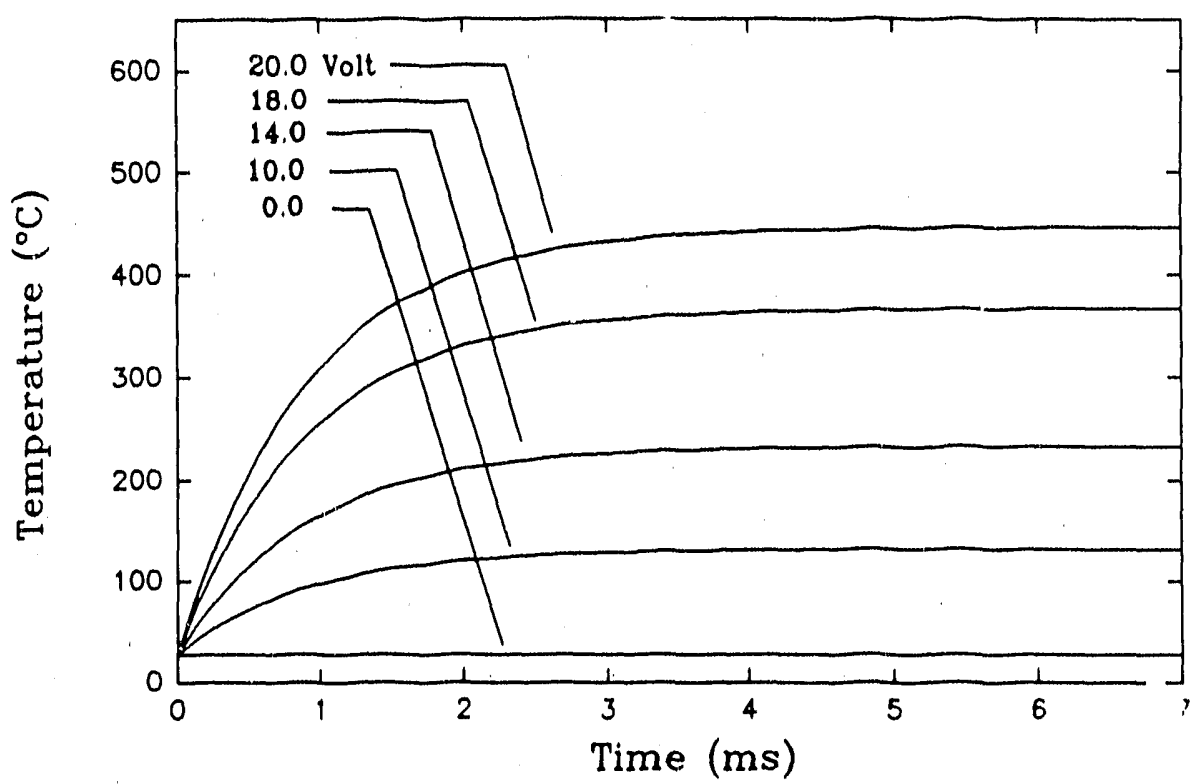

Fig. 5. Analytical estimate of the expected transient-heating-system response.

\section{PHOSPHOR CALIBRATION}

The theoretical estimate of temperature extremes shown in Fig. $5\left(27\right.$ to $\left.600^{\circ} \mathrm{C}\right)$ suggests the use of an europium-doped yttrium vanadate $\left(\mathrm{YVO}_{4}: \mathrm{Eu}\right)$ phosphor. Previous experience with this phosphor in the area of turbine-engine diagnostics (lifetime-decay measurements) shows several active spectral components within this temperature range. Figure 6 is an emission spectrum of $\mathrm{YVO}_{4}: \mathrm{Eu}$ resulting from UV excitation. ${ }^{12}$ The temperature-sensitive peaks chosen for the transient measurement are indicated as 538.9 and $617.4 \mathrm{~nm}$. These wavelengths were spectrally selected with 540 - and $620-\mathrm{nm}$ narrow-band filters with a bandwidth of $\pm 10 \mathrm{~nm}$.

The calibration of the phosphor for the ratio measurement was obtained by temporarily replacing the $\mathrm{RC}$-circuit-heating filament with a steady-state resistive-heating element. The heater was coated with the $\mathrm{YVO}_{4}:$ Eu phosphor and fitted with a thermocouple. The calibration system was allowed to equilibrate at various temperatures from 28 to $550^{\circ} \mathrm{C}$. The same data acquisition system was used to collect the data and calculate the temperature-dependent ratio. These calibration data are shown in Fig. 7. A polynomial function was fit to the calibration data to map recorded ratio data to corresponding temperature in the transient system. 


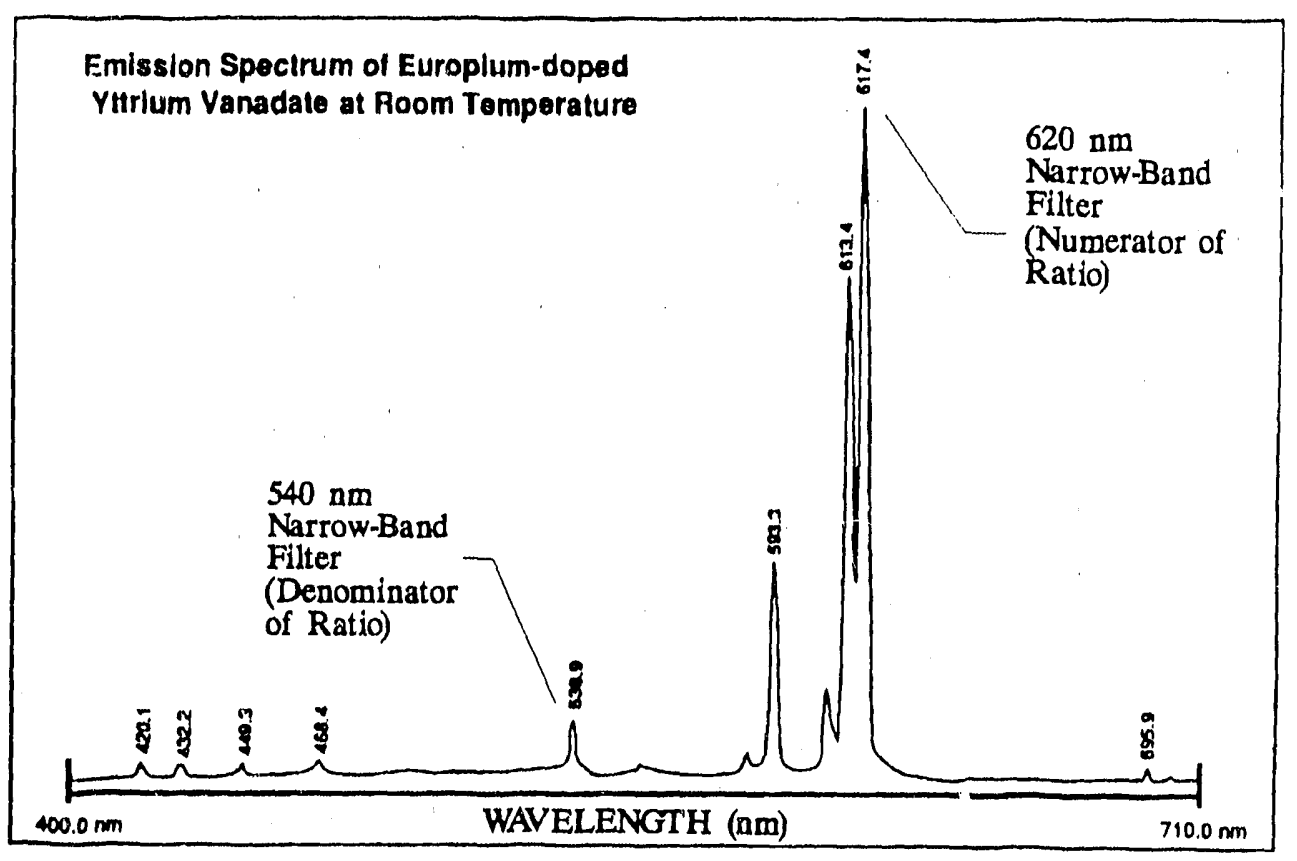

Fig. 6. Emission spectrum of the $\mathrm{YVO}_{4}$ :Eu phosphor showing the spectral peaks used for the ratio measurement.

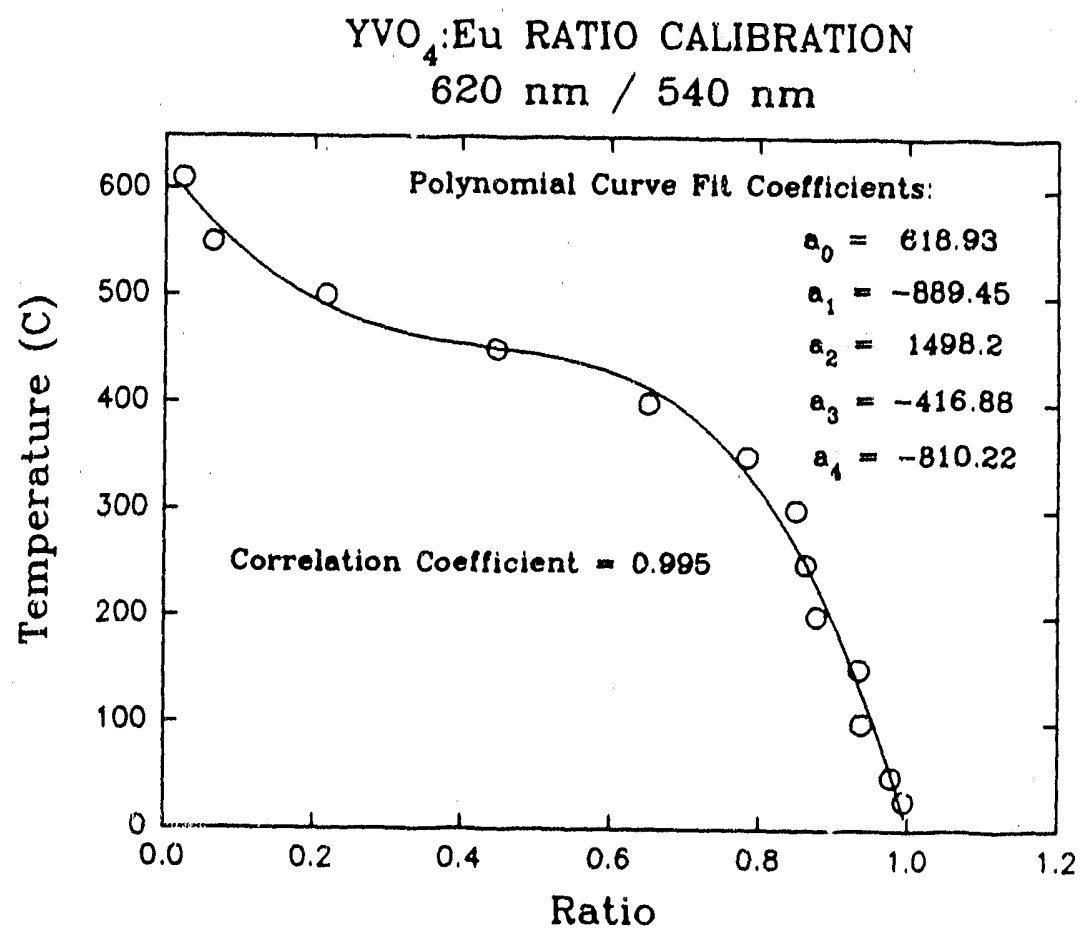

Fig. 7. Calibration curve for the ratio formed using a 540- and 620-nm narrow-band filter on the $\mathrm{YVO}_{4}$ :Eu emission. 
The mapping curve is given by the fourth-order polynom: ${ }^{2}$ of the form,

$$
T(r)=a_{0}+a_{1} r+a_{2} r^{2}+a_{3} r^{3}+a_{4} r^{4} \quad{ }^{\circ} C,
$$

where the coefficients are given by

$$
\begin{aligned}
& a_{0}=618.93 \\
& a_{1}=-889.45, \\
& a_{2}=1498.2, \\
& a_{3}=-416.88, \\
& a_{4}=-8 ! 9.22 .
\end{aligned}
$$

A fourth-order function was chosen to minimize the curve-fit error. This curve is plotted in Fig. 7, along with the calibration data.

\section{EXPERIMENI AND RFSULTS}

The transient-heating experiment was performed using the temperature-calibration function given by Eq. (5) with the RC-heated filament. Figure 8 shows a representaive heating transient where the capacitor was charged to $10.0 \mathrm{~V}$. The two separate curves where collected by the 540 - and 620 -nm narrow-band filters, and then the ratio was obtained as shown in Fig. 9. Approximately one and one-third cycies of the pseudocontinuous illumination fluorescence are presented.

Note from Fig. 9 that the measurement region begins at $\sim 2.5 \mathrm{~ms}$ and extends to $9.0 \mathrm{~ms}$. This comprises the system limit defined by the pseudocontinuous illumination source. The illumination artifact shown in the figure arises from division error between the two spectral components of the fluorescence when the light source is off. Over the transient-heating period (beginning at $-2 \mathrm{~ms}$ ), the ratio decreases as the temperature of the filament rises. The time region depicted from 0.01 to $1.15 \mathrm{~ms}$ shows a uniform room-temperature distribution. Note the signal in the measurement region has noise fluctuations that are not realistically associated with the thermal process measured. This noise is reflected in the temperature inferred by the ratios. As discussed later, future work will encompass mitigating these effects. The data in these figures were sampled at a time resolution of 19.5 $\mu \mathrm{s} / \mathrm{sample}$, an order of magnitude greater than that defined by the Nyquist criteria ${ }^{13}$ needed to determine a time response of $0.001 \mathrm{~s}$ (i.e., Nyquist sample rate $\sim 0.001 \mathrm{~s} / 2=$ $500.0 \mu \mathrm{s})$.

A heating transient was generated for different charging voltages over a range from room temperature $(0.0 \mathrm{~V})$ to a maximum temperature of $-450^{\circ} \mathrm{C}(20.0 \mathrm{~V})$. The ratio of the two spectral lines was obtained and then mapped through the temperature polynomial of Eq. (5) to produce the response curves shown in Fig. 10. Note that the depicted time domain is 2 to $9 \mathrm{~ms}$ in accordance with the informatior presented in Figs. 8 and 9 . These data can be directly compared with the analytical response predicted by Eq. (4) and shown in Fig. 5. Although time shifted, the response characteristics of the phosphor system correspond directly to the predictive model. This verifies the techni , ue as a viable method for remote-temperature monitoring of transient-heating systems. 


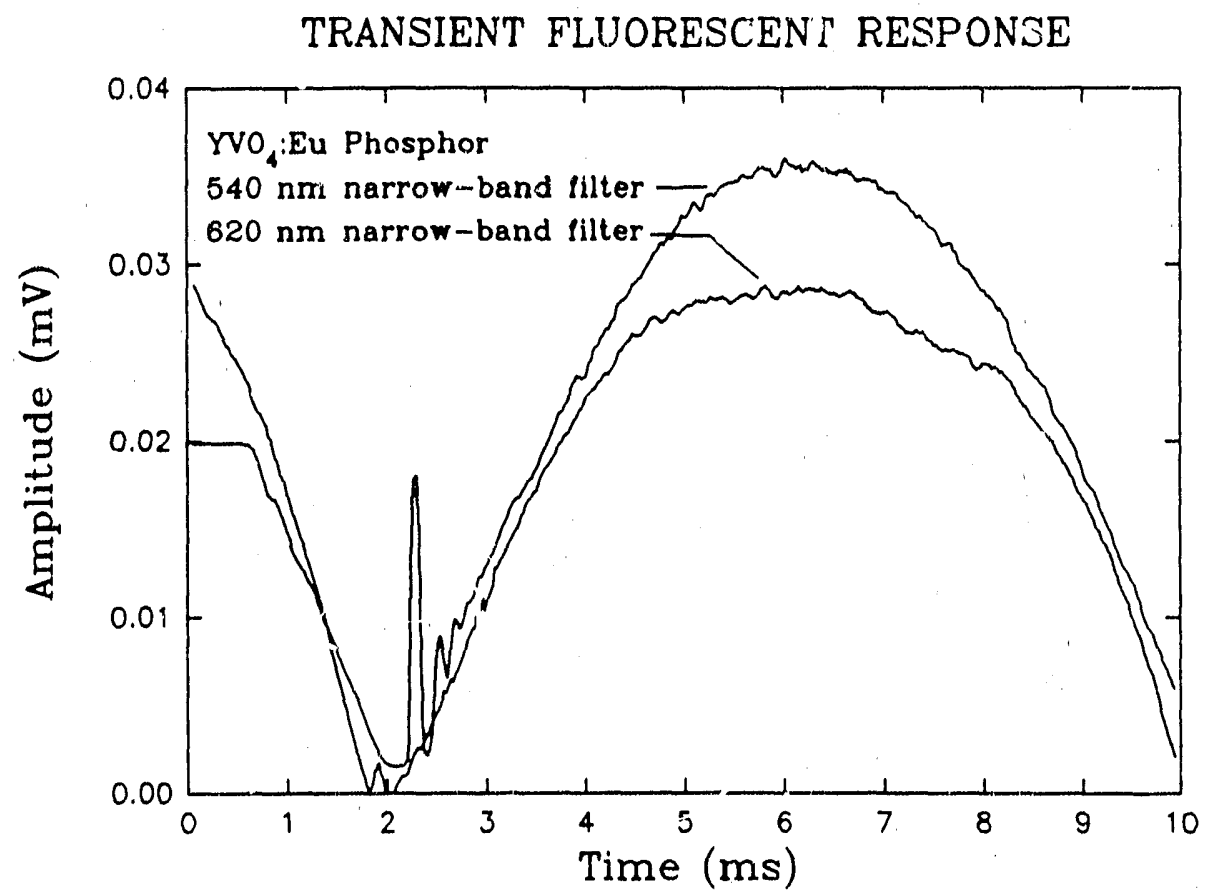

Fig. 8. Representative trace of the two selected spectral components over a single period of the UV-light source during a $10-\mathrm{V}$ heating transient.

TRANSIENT RATIO RESPONSE

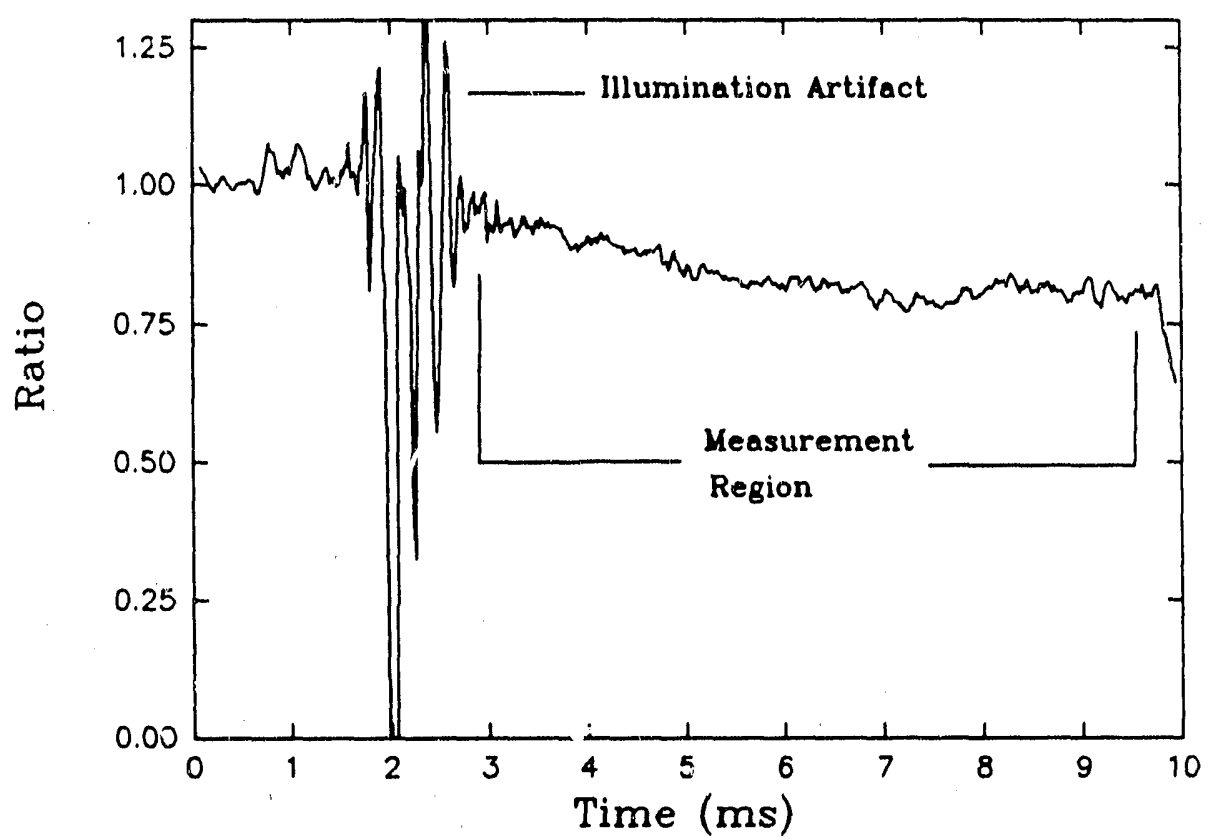

Fig. 9. Ratio of the two spectral components during a $10-\mathrm{V}$ heating transient. Note the useful measurement region of $\sim 7 \mathrm{~ms}$. 


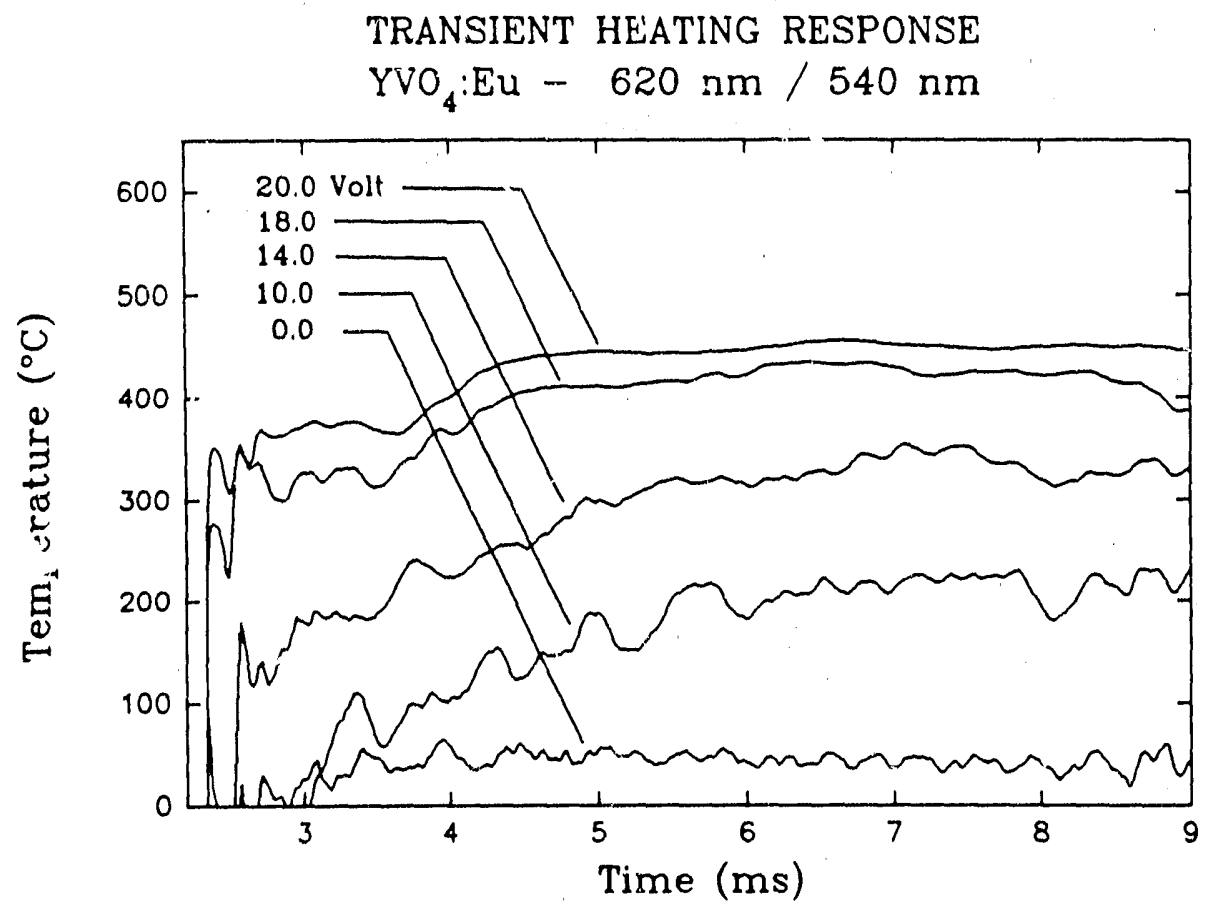

Fig. 10. Transient temperature results obtained from the RC-heating system ranging from room temperature to near $500^{\circ} \mathrm{C}$.

Figure 11 shows the heating rate of two of the trarsients as an indication of the potential heat-following characteristics. As shown, the average heat rate, followed by the thermographic phosphor system, is $\sim 100^{\circ} \mathrm{C} / \mathrm{ms}$. This follows the analytical model that preriicts a heating rate given by

$$
\frac{d}{d t} \Delta T(t)=\frac{\varepsilon^{2}}{\rho V c_{p} R} e^{-2 t / R C}
$$

Assuming the heating rates given in Fig. 11 are obtained at $\sim 1$ to $2 \mathrm{~ms}$ into the transicat, the analytical model [Eq. (6)] predicts a range of 30 to $80^{\circ} \mathrm{C} / \mathrm{ms}$ heat rates, which corresponds well to those depicted above. Note that the initial heating rates predicted by Eq. 6 (i.e., at $\mathrm{t}=0.0 \mathrm{~ms}$ ) at a 0 - to $20-\mathrm{V}$ capacitor charging range from 0 to $500^{\circ} \mathrm{C} / \mathrm{ms}$ and rapidly approach zero at $\sim 4 \mathrm{~ms}$.

From the experimental data given in this section and the analytical model of the transient heating system presented earlier, it is clear that the measurement goal ol 0.01-s temporal resolution has been exceeded by using the thermographic-phosphor method. Also, it is clear that nuch higher sampling times can allow for a still greater temporal res'slution, and higher heat-rate-following capability. An in-depth analysis of system error will be provided in future work. The main sources of signal noise associated with the given system arise in the amplification electronics (PMT, etc.) due to the weak illumination source that was used. A strong continuous-wave laser operating at an efficient phosphor excitation 


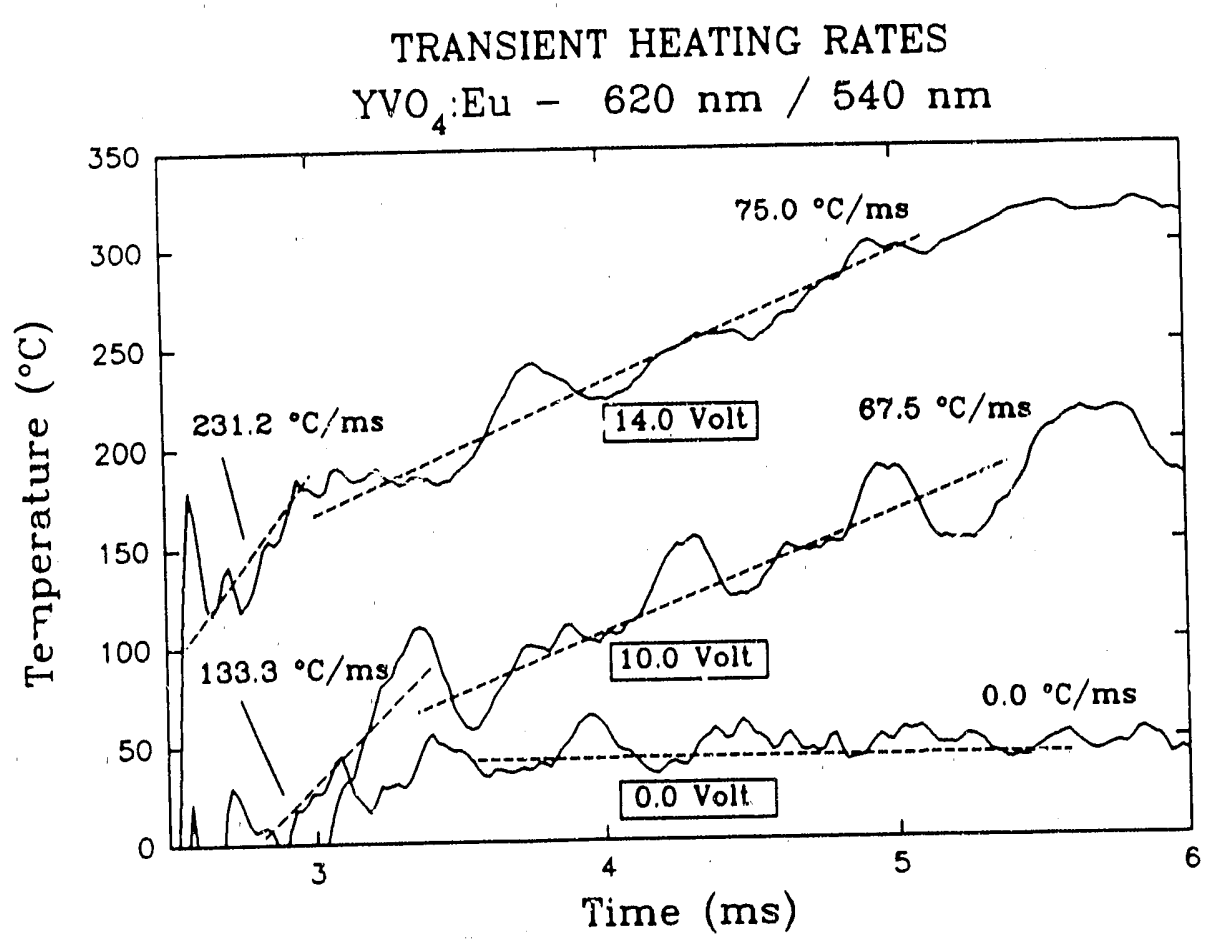

Fig. 11. Representative heating rates for 0 , 10-, and 14-V heating transients.

wavelength will improve the system signal-to-noise ratio (SNR) by a minimum of an order of magnitude. The SNR can further be improved by operating the PMT system at cryogenic temperatures. These kinds of cooled optical amplifiers are readily available and easily maintained. Using this kind of modified-data-collection system, the time resolution and temperature-following characteristics of the thermographic-phosphor-based system can be improved dramatically.

\section{CONCLUSIONS}

This laboratory project illustrated the technique of continuously monitoring dynamic temperature excursions by use of phosphor thermography. Temperature increase rates of $100^{\circ} \mathrm{C}$ or more per millisecond were measured, which illustrated a temporal response of $>0.001 \mathrm{~s}$. This exceeds by a factor of ten the goal for the project and gives strong encouragement for further development of the technology. Important to the project, too, was the establishment of a clear analytical base for fluorescent-ratio data. This was achieved, and its use is clearly demonstrated by the previous examples.

The importance of remote monitoring of dynamic temperature processes can hardly be overstated. Turbine machinery, explosive devices, gasoline engines, rotating space vehicles, and high-temperature industrial processes exemplify dynamic-temperature effects that must be monitored, understood, and controlled. Using the results of this study, specific solutions 
to dynamic-temperature-measurement problems in many application areas can be developed. In addition, the dynamic thermographic technology can be coupled with strain measurement, two-dimensional analysis, and thermometry at very high temperatures to add interrelating remote measurement tools for systems that currently cannot be effectively studied. 


\section{REFERENCES}

1. K. A. Wickersheim and R. A. Lefeuer, Luminescent Behavior of the Rare Earths in Yttrium Oxide and Related Hosts, J. Electrochem. Soc. 111(45), (1964).

2. W. H. Atkinsor. et al., Design of a Scanning Pyrometer System for Hot Section Static Structures, AFWAL-TR-86-2116. April 1987.

3. B. W. Noel et al., Evaluating and Testing Thermographic Phosphors for Turbine-Engine Temperature Measurements, AIAA-76-1761, AIAA/SAE/ASME/ASEE 23rd Joint Propulsion Conference, San Diego, California, June 29-July 2, 1987.

4. M. R. Cates et al., Applications of Pulsed-Laser Techniques and Thermographic Phosphors to Dynamic Thermometry of Rotating Surfaces, Martin Marietta Energy Systems, Inc., Oak Ridge Gaseous Diffu'sion Plant, 1984.

5. G. T. Gillies et al., Non-contact Thermometry via Laser Pumped, Thermographic Phosphors: Characterizations of Systematic Errors and Industrial Applications, K/ETAC32, Martin Marietta Energy Systems, Inc., Oak Ridge Gaseous Diffusion Plant, October 1987.

6. K. W. Tobin et al., Remote High-Temperature Thermometry of Kotating Test Blades Using YVO $: E u$ and $\mathrm{Y}_{2} \mathrm{O}_{3}: \mathrm{Eu}$ Thermographic Phosphors, Paper 88-3147, AIAA/SAE/ASME 24th Joint Propulsion Conference, July, 1988.

7. K. W. Tobin et al., Engine Testing of Thermographic Phosphors. Part 1: Pratt \& Whitney Fixed-Blade Test. Part 2: Virginia Polytechnic Institute Turbine-Blade Test., ORNL/ATD31, Martin Marietta Energy Systems, Inc., Oak Ridge National Laboratory, 1990.

8. C. M. Simmons et al., Low-Temperature Phosphor Thermometry: Calibration of Europium-Doped, Lanthanum Oxysulfide Between Room Temperature and $-194^{\circ} \mathrm{C}$, ORNL/ATD-25, Martin Marietta Energy Systems, Inc., Oak Ridge Natl. Lab., February 1990.

9. K. W. Tobin et al., Evaluation of Thermographic Phosphor Technology for Aerodynamic Model Testing, ORNL/ATD-40, Martin Marietta Energy Systems, Inc., Oak Ridge Natl. Lab., August 1990.

10. D. Barnaal, Analog and Digital Electronics for Scientific Application, Breton Publishers, North Scituate, Massachusetts, 1982.

11. F. P. Incropera and D. P. DeWitt, Fundamentals of Heat Transfer, John Wiley \& Sons, New York, 1981.

12. A. R. Bugos, Characterization of the Emission Properties of Thermographic Phosphors for Use in High Temperature Sensing Applications, Masters Thesis, University of Tennessee, Knoxville, Tennessee, May 1989.

13. A. V. Oppenheim and R. W. Schafer, Digital Signal Processing, Prentice-Hall, Inc., Englewood Cliffs, New Jersey, 1975. 

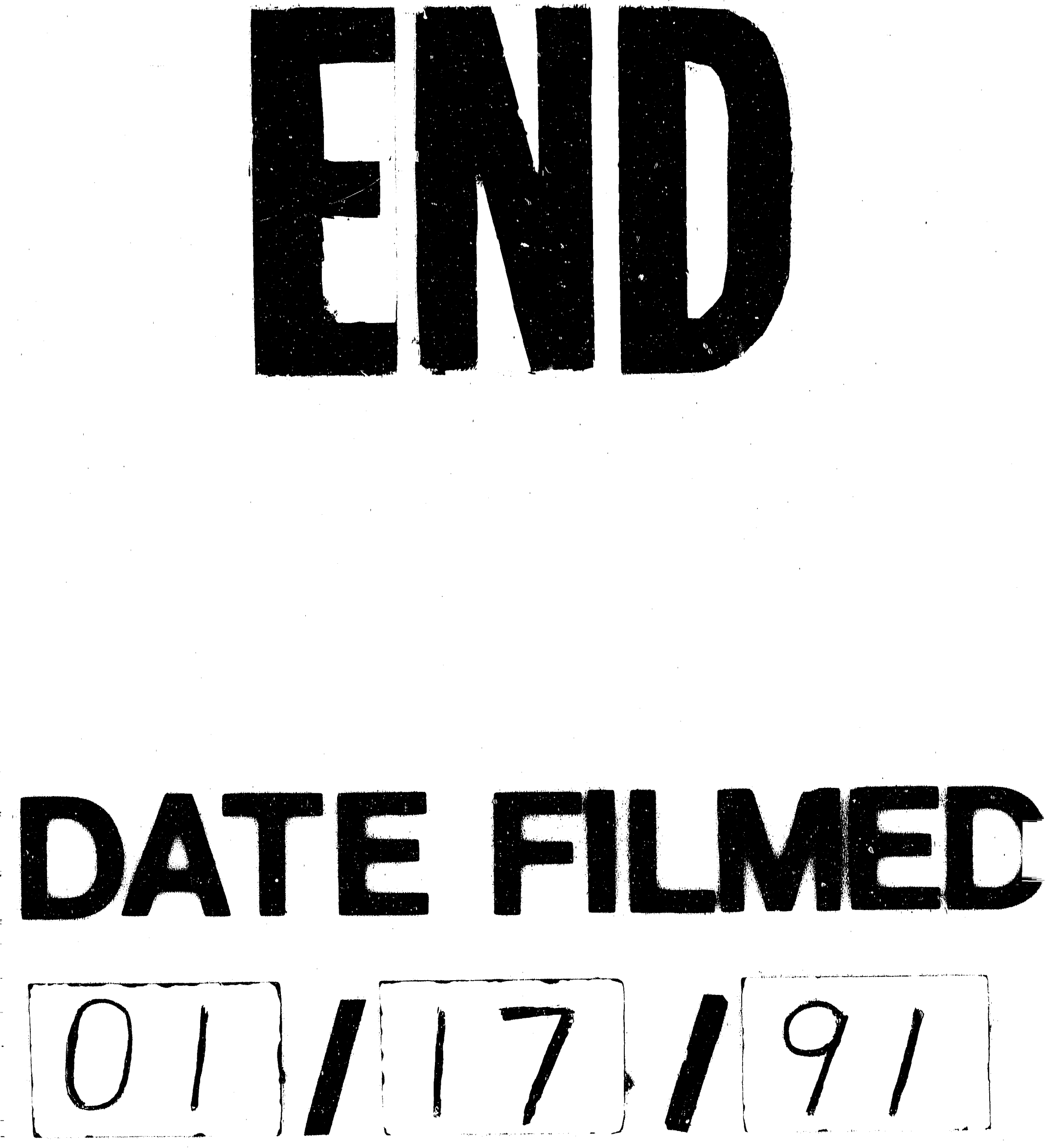
